\title{
Us and them: Memory advantages in perceptually ambiguous groups
}

\author{
Nicholas O. Rule and Nalini Ambady \\ Tufts University, Medford, Massachusetts \\ REGINALd B. AdAMs, JR. \\ Pennsylvania State University, University Park, Pennsylvania \\ AND \\ C. Neil Macrae \\ University of Aberdeen, Aberdeen, Scotland
}

\begin{abstract}
Ingroup advantages and outgroup deficits in perception and memory are well-established in research on race, gender, and other ostensibly identifiable social categories. The present study extended this research to a social category that is not as perceptually apparent: male sexual orientation. Consistent with hypotheses, an interaction of participant sexual orientation and image sexual orientation revealed an ingroup enhancement and outgroup deficit for memory of faces that participants perceived - both accurately and inaccurately — as belonging to either their ingroup or outgroup in a subsequent task. Additionally, parallel effects were found for the accurate identification of sexual orientation - a finding consistent with previous literature. The present data highlight the importance of social categorization for subsequent memory and suggest that the underlying cognitive machinery responsible for the recognition of groups may be co-opted for other relevant social applications.
\end{abstract}

We are usually very good at deciding whether someone is of the same race, gender, or age as ourselves. Not all social categories are easy to discern, however. Do the perceptual and cognitive processes underlying social categorization work for ambiguous others just as well as they do for perceptually obvious ingroup and outgroup members? Although this question has, to date, gone largely unaddressed in the social cognition literature, we believe the answer is yes.

It is well known that people show increased memory and attention for those with whom they share a social identity (see Sporer, 2001). Moreover, people also tend to view such ingroup members as more diverse and individuated than those in any given outgroup, regarding the latter as relatively indistinct and homogeneous (Allen \& Wilder, 1975; Wilder \& Allen, 1974, 1978). Undoubtedly the most highly studied ingroup/outgroup divisions are those that pertain to race. Myriad studies have examined the behavioral manifestations and cognitive effects of the own-race bias and other-race effect with regard to attention and memory (see Meissner \& Brigham, 2001, for review and meta-analysis). A particularly well-known example comes from the person-perception literature in social cognition, which examines own-race memory enhancement using a signal-detection paradigm (e.g., Lindsay, Jack, \& Christian, 1991). On the whole, these studies have consistently shown that memory and recall for own-race persons is enhanced in both accuracy and reaction time than for other-race persons (see also Bothwell, Brigham, \& Malpass, 1989; Sporer, 2001). Is it possible, however, that these effects might apply to groups that are not so perceptually obvious?

The preferred attention and cognitive resources allocated toward one's ingroup are by no means unique to racial groups, despite the plethora of research that has been conducted in that area. Although substantially less studied, similar ingroup effects have also been found for the discrimination of gender (Cross, Cross, \& Daly, 1971; Wright \& Sladden, 2003). For example, participants who viewed Black and White faces of both genders showed not only the expected own-race bias but a significant own-gender bias in detection accuracy, as well (Slone, Brigham, \& Meissner, 2000). Similarly, participants also show ingroup advantages in speed of classifying faces on gender and race (Smith \& Zarate, 1990). In addition, ingroup effects based on age have also been demonstrated for youthful (university students), middle-aged, and elderly participants (Rodin, 1987; Wright \& Stroud, 2002).

Although classifying individuals by group identity is believed to occur almost immediately upon encountering a person (Macrae \& Bodenhausen, 2000; Macrae, Milne, \& Bodenhausen, 1994), the empirical data that support this finding seem true only of perceptually apparent groups. Of those identities reviewed above for having shown in- 
group facilitation and outgroup deficits (race, sex, and age), all possess distinct physical features that distinguish the groups (Brown \& Perrett, 1993; Ellis, Deregowski, \& Shepherd, 1975; Roberts \& Bruce, 1989).

Therefore, while the previous work done in this area has focused largely on race as a defining factor of the ingroup/ outgroup distinction, the present work explores whether such ingroup advantages as the "own-race bias" extend beyond perceptually apparent social categories. We do this by testing ingroup advantages for a much less explicit social category membership, that of sexual orientation. ${ }^{1}$

Sexual orientation presents a naturally occurring set of perceptually ambiguous group boundaries within the realm of social categorization. Although previous work has shown that sexual orientation can be accurately determined from dynamic video and still photographs (Ambady, Hallahan, \& Conner, 1999) — as well as from static images of the face alone (Rule, Ambady, \& Macrae, 2007) — these effects are subtle. Therefore, if the perceptual and memory advantages common to racial distinctions also uphold for sexual orientation, this finding might lend empirical support to previous theories that the cognitive machinery responsible for these advantages extends beyond the categorization of race, is a heuristic process deeply embedded in social cognition, and can be readily attuned to subtle group distinctions (see Cosmides, Tooby, \& Kurzban, 2003; Kurzban, Tooby, \& Cosmides, 2001).

We suspect that the enhanced effects in perception and memory might occur even when the markers of group membership are relatively concealed or ambiguous, as they are with sexual orientation. Thus, we anticipate that participants' perceptions of the target faces' sexual orientation might affect whether a face is subsequently remembered. As such, the present study examines memory advantages for homosexual and heterosexual male participants viewing images of gay and straight target faces.

\section{METHOD}

\section{Participants}

Forty-five self-identified homosexual $(N=22)$ and heterosexual $(N=23)$ male college students participated for partial course credit in a psychology class or were paid $\$ 5$. Paid participants were volunteers from a registry of students interested in participating in experiments for cash that had previously provided demographic information as part of a prescreening questionnaire. This information assisted us in assuring that equal numbers of heterosexual and homosexual males were recruited for the experiment.

\section{Stimuli}

The images consisted of 40 homosexual and 40 heterosexual males obtained from public, online personal ads posted for use in various major cities across the U.S. Men in the images were therefore self-defined for sexual orientation, were anonymous, and were available to the public domain. Images were taken from the 18-30 age group on the personals Web sites. Only photos of headshots were downloaded for use. Although hundreds of images were initially collected, only those images presenting a directly oriented face free of any facial alterations, such as jewelry, spectacles, or facial hair, were selected, resulting in 45 homosexual and 45 heterosexual images. Forty images were randomly selected from each target group for use in the present study. The images were removed from their original context and placed onto a white background. Targets' ears and hair were retained in the cropping while all other extra-facial information (e.g., neck) was removed. Images were then grayscaled and standardized to $3 \times 5$ in. dimensions. In order to preserve anonymity and respect privacy, none of the targets' sexual orientations were disclosed to participants. Further, none of the photos were obtained from the local geographic area.

\section{Procedure}

Stage 1. Images were presented using PsyScope 1.2.5 PPC. Participants were first instructed that they would see a series of faces appear on the computer screen and that they were to passively view each photograph presented (incidental encoding). Forty images (20 gay, 20 straight) were presented individually and in random order and shown for 3,000 msec. Each image was preceded by a $500 \mathrm{msec}$ blank screen and a $500 \mathrm{msec}$ fixation cross.

Stage 2. Once the encoding session was complete, participants received a new set of instructions, asking them to spend the next 2 min working on a word-search that was placed next to the computer. The content of the word-search was irrelevant to the experiment and identical for every participant. The purpose of this fillertask was to clear the participants' working memory so as to reduce recency effects upon recognition. Once the $2 \mathrm{~min}$ had elapsed, the computer alerted the participant by emitting an electronic sound and then presented the participant with a new set of instructions.

Stage 3. Participants were asked to rest their index fingers on the " $g$ " and " $h$ " keys of the computer's keyboard and to indicate by keypress whether they had seen the face presented to them in the prior portion of the experiment. The assignment of keys to affirmative (seen before) and negative (not seen before) responses was counterbalanced across participants and participants were requested to make their decisions as quickly as possible. A reminder of the assignment of keys was always present below each image during the recognition session in order to reduce confusion and error. In this second presentation of faces, the participants saw all 80 faces used in the experiment (40 previously presented, 40 foils) in random order. The apportionment of targets and foils was counterbalanced across participants so that half saw the first set of faces (Gay and Straight Images 1-20) as targets during encoding, whereas the other half saw the second set of faces (Gay and Straight Images 21-40) as targets during encoding.

Stage 4. Once the recognition session was complete, participants were asked to engage in one last task: identifying the sexual orientation of the men in the photographs. This was the first point at which sexual orientation was mentioned as a factor in the experiment. Participants were encouraged to base their decision on what "most people" or "society" might label the person presented to them. No participant reported discomfort in completing this task. Once the session was complete, participants were asked to volunteer their own sexual orientation with the option of no response. Participants were then debriefed, compensated, and asked not to discuss the experiment with others.

\section{RESULTS}

\section{Sexual Orientation}

Judgments of sexual orientation were calculated for accuracy based on the dichotomous ratings given in Stage 4. Previous research by Ambady et al. (1999) has indicated that gay and lesbian participants are more accurate at judging sexual orientation than are heterosexual participants. The accuracy reported in their study for full-body still images (54\%) was quite low compared to conditions using video clips as stimuli. The present study shows a higher level of accuracy (62\%; see Table 1), even though the present stimuli (still faces) contained much less information than the still frames of full-body, dynamic behavior used by Ambady et al. 
Table 1

Accuracy Scores for the Judgment of Sexual Orientation by Homosexual and Heterosexual Participants in Stage 4 of the Experiment

\begin{tabular}{lccc}
\hline & \multicolumn{3}{c}{ Participants } \\
\cline { 2 - 4 } Images & Homosexual & Heterosexual & All \\
\hline Gay & .61 & .48 & .54 \\
Straight & .68 & .71 & .70 \\
All & .64 & .60 & .62 \\
\hline
\end{tabular}

Overall, participants were more accurate in categorizing heterosexual images $(70 \%)$ than homosexual images $(54 \%)$. This effect is likely due to the conception of heterosexuality as the default category, with judgments of homosexuality reserved only for cases of high certainty (see also Smith \& Zarate, 1992). This bias is logical in terms of base rates for sexual orientation in the population. It is also safe, given that misidentifying a heterosexual as homosexual can be seen as derogatory and sometimes brings violent consequences (see Herek, Cogan, \& Gillis, 2002).

Consistent with Ambady et al.'s (1999) work, homosexual participants outperformed heterosexual participants. Data were converted to $d^{\prime}$ scores in order to correct for the proclivity to rate faces as one sexual orientation more frequently than the other. Again, homosexual participants were more accurate at judging sexual orientation: $M_{d^{\prime}}$ homosexual $=.77(.07), M_{d^{\prime} \text { heterosexual }}=.55(.07)[t(43)=$ $2.35, p<.025, r=.34]$. Moreover, criterion bias $(c)$ was significantly greater for the heterosexual participants than the homosexual participants $\left[M_{c}\right.$ heterosexual $=-.33(.07)$, $M_{c \text { homosexual }}=-.11(.07) ; t(43)=2.21, p<.05, r=$ $.32]$, reflecting heterosexual participants' propensity to label images as straight more often than gay. Thus, heterosexual participants appear to be worse at judging sexual orientation accurately because they are more biased toward believing that targets are straight.

\section{Actual Memory}

The data for memory were analyzed on three levels. The first analysis was of the actual hit and false alarm rates, regardless of subsequent categorization of the faces as gay or straight. Frequencies for hits (correctly remem-

Table 2

Mean Hit (Correctly Remembered) and False Alarm (Falsely Remembered) Frequencies for Participant Sexual Orientation As a Function of Image Sexual Orientation for the Three Memory Analyses

\begin{tabular}{|c|c|c|c|c|c|}
\hline \multirow{3}{*}{$\begin{array}{l}\text { Memory } \\
\text { Analysis }\end{array}$} & \multirow[b]{3}{*}{ Participants } & \multicolumn{4}{|c|}{ Images } \\
\hline & & \multicolumn{2}{|c|}{ Gay } & \multicolumn{2}{|c|}{ Straight } \\
\hline & & $\mathrm{H}$ & $\overline{F A}$ & $\overline{\mathrm{H}}$ & FA \\
\hline \multirow[t]{2}{*}{ Actual } & Homosexual & .73 & .29 & .68 & .15 \\
\hline & Heterosexual & .66 & .29 & .60 & .13 \\
\hline \multirow[t]{2}{*}{ Perceived } & Homosexual & .40 & .12 & .30 & .11 \\
\hline & Heterosexual & .32 & .13 & .32 & .09 \\
\hline \multirow[t]{2}{*}{ Corrected } & Homosexual & .80 & .31 & .63 & .17 \\
\hline & Heterosexual & .67 & .31 & .61 & .10 \\
\hline
\end{tabular}

Note-Actual: target self-identified sexual orientation. Perceived: sexual orientation as perceived by participants. Corrected: sexual orientation accurately classified by participants. bered) and false alarm (falsely remembered) images were computed using the $d^{\prime}$ statistic for signal-detection (see Table 2 for hit and false alarm rates).

These $d^{\prime}$ scores were then subjected to repeated measures ANOVA with participant sexual orientation as a between-participants factor and image sexual orientation as a two-level repeated measure. Results show a main effect of target sexual orientation, whereby images of heterosexuals were remembered better by both homosexual and heterosexual participants $[F(1,89)=5.15, p<.03$, $r=.23]$. Simple effects (Bonferroni-corrected) $t$ tests indicated that the main effect was driven largely by heterosexuals' preferential memory for ingroup images $[t(22)=$ $3.39, p=.002, r=.59$ ]. Homosexual participants, however, showed no difference in memory for the gay and straight faces $[t(21)=1.91$, n.s.; see Figure 1]. It has previously been shown that, due to their oppressed status, racial minorities often fail to show memory advantages for their own ingroups-a consequence of heightened attentiveness and exposure to the majority group (Anthony, Copper, \& Mullen, 1992; Meissner \& Brigham, 2001). Therefore, the presence of an ingroup effect for the heterosexual majority and asymmetrical lack of effect for the homosexual minority is not surprising.

Participants also showed a much higher level of response bias $(c)$ as a factor of image type $[F(1,89)=20.08$, $p<.001, r=.43]$. Simple effects showed that both homosexuals $[t(21)=4.35, p<.001, r=.69]$ and heterosexuals $[t(22)=5.98, p<.001, r=.79]$ were significantly more likely to say "yes" to straight stimuli during Stage 3; indicating that they remembered, or believed to remember, straight images more often than gay images.

\section{Perceived Memory}

Compared to the categorization of race and gender, however, accuracy in detecting sexual orientation is very low-albeit above chance (see above analysis). Therefore, a second analysis was conducted to examine the effect that perceived group identity had upon participants' memory for the images. Each participant's response rate for the homosexual and heterosexual image groups was based on the number of images remembered (hits) or falsely remembered (false alarms) depending on how each individual participant perceived the men's sexual orientations. Specifically, hit and false alarm rates were calculated based on who each participant identified as gay and straight. This yielded two pairs of hit and false alarm values per participant: one for the gay images and one for the straight images.

These data were again computed into $d^{\prime}$ scores and subjected to repeated measures ANOVA with participant sexual orientation as a between-participants factor and image sexual orientation as a two-level repeated measure. A significant interaction between image sexual orientation and participant sexual orientation $[F(1,89)=5.57$, $p<.05, r=.24$ ] was observed, indicating an ingroup advantage. Those faces perceived as homosexual were better remembered by homosexuals while those faces perceived as heterosexual were better remembered by heterosexuals (see Figure 2). Simple effects (Bonferroni-corrected) 


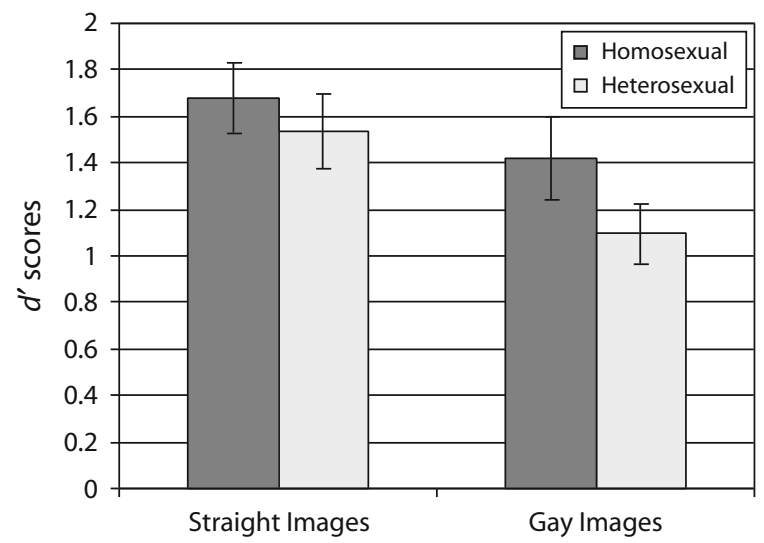

Figure 1. Means and standard errors for $d^{\prime}$ scores according to targets' self-identified sexual orientation, regardless of participants' perceptions of target sexual orientation.

$t$ tests indicate that heterosexuals were significantly better at remembering images perceived as belonging to their ingroup $[t(22)=3.56, p=.002, r=.61]$, while no other comparisons reached significance. The lack of a parallel simple effect for homosexuals again provides some intrigue as to why homosexuals do not show as strong a difference in memory sensitivity for their own group. The most immediate explanation is that of differences in perception resulting from a minority status, as above. A secondary explanation may be that homosexuals are motivated by romantic interests that cause them to preferentially attend to, and subsequently encode and remember, all male faces. That said, they do still show a nonsignificant tendency toward remembering other gay targets, which could reflect an even higher interest in those persons holding a higher potential for mating.

Measures of response bias $(c)$ were also analyzed in a $2 \times 2$ ANOVA design. Results of this analysis indicate a main effect in response bias for image type $[F(1,89)=$ $9.11, p<.01, r=.31]$, which was principally the result of homosexual participants' tendency to believe that they had previously seen the straight images, as discussed in the memory findings above $[t(21)=4.60, p<.001$ (Bonferroni $\alpha=.0125$ ), $r=.71$ ]; no other simple effects reached significance.

\section{Corrected Memory}

Since it is based on perceived categorization, the above analysis may simply reflect a tendency to label the remembered targets as "like me." Thus, the data were reanalyzed to account for participants' accuracy in judgments of sexual orientation. To further reduce the effects of ambiguity, we included in the analysis only images that participants had accurately identified as gay and straight. For example, if Participant 1 had correctly classified 30 targets as gay and 25 targets as straight, only these 55 images would be included in the analysis of his data. Hits for the gay images would then be calculated based on the number of hits that were correctly identified as gay in Stage 4 , divided by the total number of target (previously shown) images that Participant 1 correctly identified as gay. Although this particular analysis introduces greater variance between individual participants, it is more theoretically conservative because it accounts for the high number of errors that individuals make in categorizing based on sexual orientation.

Results replicated the previous effect, showing a significant interaction between image sexual orientation and participant sexual orientation $[F(1,89)=4.36, p<.05$, $r=.22]$. The data reflect a significant ingroup advantage in memory for faces: those faces accurately perceived as homosexual were better remembered by homosexuals while those faces accurately perceived as heterosexual were better remembered by heterosexuals (see Figure 3 ). Simple effects analysis of the interaction suggest that a large contribution of this effect is due to heterosexual participants' better memory for ingroup faces over outgroup (gay) faces $[t(22)=3.09, p=.005, r=.55]$. In addition, a main effect of response bias $(c)$ was found for image sexual orientation $[F(1,89)=28.98, p<.001, r=.50]$, with both homosexual $[t(21)=5.04, p<.001, r=.74]$ and heterosexual $[t(21)=4.95, p<.001, r=.73]$ participants showing high levels of bias for responding that they had previously seen the straight images (no simple effects were found between participants).

\section{DISCUSSION}

The present work expands upon the preferential memory and attention afforded to members of one's racial ingroup by demonstrating these effects in a naturally occurring social distinction that is both subtle and perceptually ambiguous. Whereas previous studies showing similar variants of subtlety have used artificially constructed social groups (see Ostrom \& Sedikides, 1992, for review), the present work achieves such effects within a natural, rather than arbitrarily constructed, social class. Considering, then, that the work on social categorization has looked primarily at perceptually obvious groups, the present results suggest that categorization occurs even for groups with less apparent, perhaps even nonconsciously recognized, physical markers. Such an effect speaks to the proposed automatic-

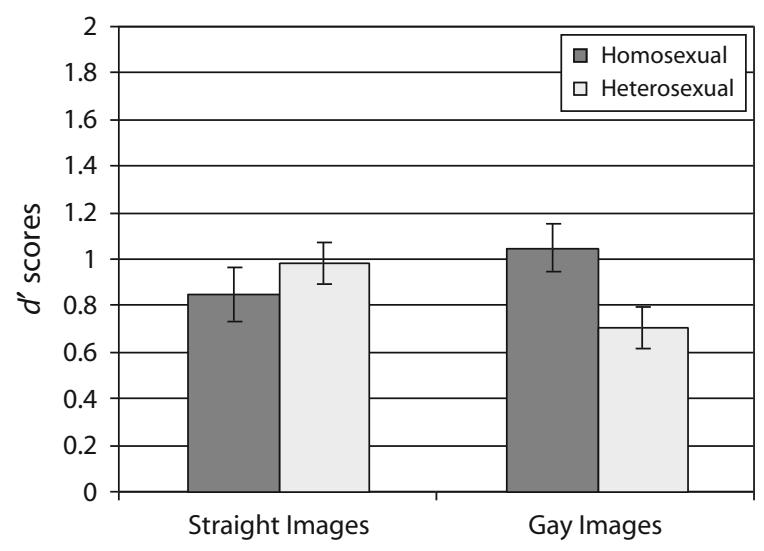

Figure 2. Means and standard errors for $d^{\prime}$ scores according to targets' perceived sexual orientation by homosexual and heterosexual participants. 


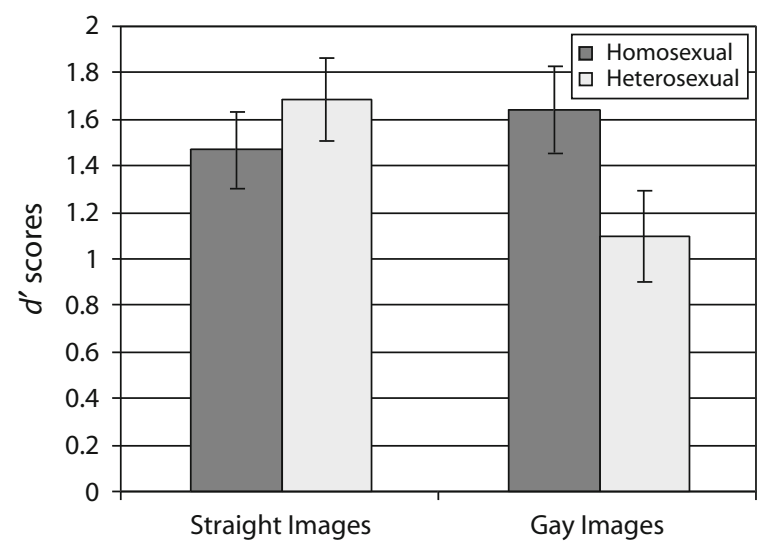

Figure 3. Means and standard errors for $d^{\prime}$ scores when targets' sexual orientation was accurately identified by participants.

ity of person categorization (see Macrae \& Bodenhausen, 2000; Macrae et al., 1994).

Thus far, the categorization of ambiguous groups has gone relatively unexplored in social cognition. Here we demonstrate that incidental memory effects are achieved based upon the outcome of this categorization when applied to a perceptually ambiguous group; thereby highlighting the role of social categorization as an important antecedent to remembering others. Categories such as race and gender are presumably easily categorized accurately. As we and others (Ambady et al., 1999; Rule et al., 2007) have shown, sexual orientation is classified at an average of $62 \%$ accuracy. This $38 \%$ error, then, has somewhat disrupted the present effects but also allows us to observe the role of social categorization as an important antecedent to remembering others. In turn, these effects also support the idea of social groups as coalitional alliances (see Cosmides et al., 2003; Kurzban et al., 2001), as they show that the cognitive representations of groups are not fixed but, rather, are variably dependent upon the recognition of others as ingroup or outgroup members. This presents an interesting future direction for this work, as well: Namely, would participants show better memory for those persons that they were explicitly told belonged to their group? If so, this would more directly support the claims that groups can be identified and defined by attending to malleable coalitional alliances, rather than relying upon the incidental — and only moderately accurate-ability to discern this information from subtle physical markers.

One interesting finding was the asymmetry displayed between homosexual and heterosexual participants' performances. In terms of the accuracy data reported here, we replicate Ambady et al.'s (1999) effect showing that homosexuals are better than heterosexuals at judging sexual orientation. This difference is likely the result of increased attunement to sexual orientation that is required of homosexuals because of their minority status. Not only are homosexuals presumably more vigilant at detecting sexual orientation in others, they are also likely to have experienced more feedback in making such judgments. This too, then, explains homosexual participants' significantly lower bias for detecting sexual orientation.
Similarly, asymmetry between homosexuals' and heterosexuals' performance was revealed in their memory for faces, as well. Heterosexuals showed higher sensitivity toward remembering their ingroup members-the expected effect. Homosexuals, however, were also fairly prone to remember straight targets. Homosexuals' better memory overall is not a surprising effect, given that this is common of minority group members (Anthony et al., 1992; Meissner \& Brigham, 2001) and as their interest in other men is expected to be high for reasons related to mating (see also Rodin, 1987, Experiment 4). It is probable that homosexual participants processed the faces of the men in this study longer or more deeply than did the heterosexual participants, leading to greater ease of recognition later in the experiment. Conversely, heterosexual participants appear to have treated homosexual targets with a sort of "cognitive disregard" (Rodin, 1987), exhibiting better memory for members of their own group.

Therefore, although the present work is not unique in demonstrating that nonracial groups are susceptible to the behavioral effects of outgroup homogeneity, the study is novel in that it is the first to show similar effects in a group that is naturally occurring and perceptually ambiguous. Despite the absence of an ingroup effect that is directly parallel to those observed with race and other perceptually ostensible groups, the present work presents interesting implications for the importance of social categorization in the encoding and memory for photos of faces. We remember better those who we perceive-both accurately and inaccurately - as like us. These findings are not only informative to our understanding of phenomena such as the own-race bias but also provide insight to the cognitive machinery that is responsible for delineating social groups.

\section{AUTHOR NOTE}

This research was supported in part by an NSF Graduate Research Fellowship to N.O.R. and a National Institute of Mental Health Research Grant R01 MH70833-01A1 to N.A. The authors thank Max Weisbuch, Kristin Pauker, Caren Rotello, Dan Wright, and two anonymous reviewers for helpful comments and feedback on this and earlier drafts. Correspondence concerning this article should be addressed to N. O. Rule, Department of Psychology, Tufts University, 490 Boston Avenue, Medford, MA 02155 (e-mail: nicholas.rule@tufts.edu).

\section{REFERENCES}

Allen, V. L., \& Wilder, D. A. (1975). Categorization, belief similarity, and intergroup discrimination. Journal of Personality \& Social Psychology, 32, 971-977.

Ambady, N., Hallahan, M., \& Conner, B. (1999). Accuracy of judgments of sexual orientation from thin slices of behavior. Journal of Personality \& Social Psychology, 77, 538-547.

ANThony, T., CopPer, C., \& Mullen, B. (1992). Cross-racial facial identification: A social cognitive integration. Personality \& Social Psychology Bulletin, 18, 296-301.

BothWEll, R. K., Brigham, J. C., \& Malpass, R. S. (1989). Cross-racial identification. Personality \& Social Psychology Bulletin, 15, 19-25.

Brown, E., \& PERretT, D. I. (1993). What gives a face its gender? Perception, 22, 829-840.

Cosmides, L., Tooby, J., \& Kurzban, R. (2003). Perceptions of race. Trends in Cognitive Sciences, 7, 173-179.

Cross, J. F., Cross, J., \& DALY, J. (1971). Sex, race, age, and beauty as factors in recognition of faces. Perception \& Psychophysics, 10, 393-396. 
Ellis, H. D., Deregowski, J. B., \& Shepherd, J. W. (1975). Descriptions of white and black faces by white and black subjects. International Journal of Psychology, 10, 119-123.

Herek, G., Cogan, J. C., \& Gillis, J. R. (2002). Victim experiences in hate crimes based on sexual orientation. Journal of Social Issues, 58, 319-339.

KuRZBAN, R., Toовy, J., \& Cosmides, L. (2001). Can race be erased?: Coalitional computation and social categorization. Proceedings of the National Academy of Sciences, 98, 15387-15392.

LinDSAY, D., JACK, P. C., \& Christian, M. A. (1991). Other-race face perception. Journal of Applied Psychology, 76, 587-589.

Macrae, C. N., \& Bodenhausen, G. V. (2000). Social cognition: Thinking categorically about others. Annual Review of Psychology, 51, 93-120.

Macrae, C. N., Milne, A. B., \& Bodenhausen, G. V. (1994). Stereotypes as energy-saving devices: A peek inside the cognitive toolbox. Journal of Personality \& Social Psychology, 66, 37-47.

MEISSNER, C. A., \& BrighaM, J. C. (2001). Thirty years of investigating the own-race bias in memory for faces: A meta-analytic review. Psychology, Public Policy, \& Law, 7, 3-35.

Ostrom, T. M., \& Sedikides, C. (1992). Out-group homogeneity effects in natural and minimal groups. Psychological Bulletin, 112, 536-552.

RoBerts, T., \& Bruce, V. (1989). Feature saliency in judging the sex and familiarity of faces. Perception, 17, 475-581.

Rodin, M. J. (1987). Who is memorable to whom: A study of cognitive disregard. Social Cognition, 5, 144-165.

Rule, N. O., Ambady, N., \& Macrae, C. N. (2007). On judging books by their covers: Sexual orientation is accurately perceived at $50 \mathrm{msec}$. Manuscript under review.

Simon, B., Glassner-Bayerl, B., \& Stratenwerth, I. (1991). Stereotyping and self-stereotyping in a natural intergroup context: the case of heterosexual and homosexual men. Social Psychology Quarterly, 54, 252-266.
Slone, A. E., Brigham, J. C., \& Meissner, C. A. (2000). Social and cognitive factors affecting the own-race bias in Whites. Basic \& Applied Social Psychology, 22, 71-84.

Smith, E. R., \& Zarate, M. A. (1990). Person categorization and stereotyping. Social Cognition, 8, 161-185.

SMith, E. R., \& ZARATE, M. A. (1992). Exemplar-based model of social judgment. Psychological Review, 99, 3-21.

SPORER, S. L. (2001). Recognizing faces of other ethnic groups: An integration of theories. Psychology, Public Policy, \& Law, 7, 36-97.

Wilder, D. A., \& Allen, V. L. (1974). Effects of social categorization and belief similarity upon intergroup behavior. Personality \& Social Psychology Bulletin, 1, 281-283.

Wilder, D. A., \& Allen, V. L. (1978). Group membership and preference for information about others. Personality \& Social Psychology Bulletin, 4, 106-110.

Wright, D. B., \& Sladden, B. (2003). An own gender bias and the importance of hair in face recognition. Acta Psychologica, 114, 101-114.

WRIGHT, D. B., \& Stroud, J. N. (2002). Age differences in lineup identification accuracy: People are better with their own age. Law \& Human Behavior, 26, 641-654.

\section{NOTE}

1. See Ostrom and Sedikides (1992) for a review of outgroup homogeneity effects in minimal groups and subtle natural groups where neither visual recognition/perception nor memory were factors; see also Simon, Glassner-Bayerl, and Stratenwerth (1991) for findings specific to sexual orientation.

(Manuscript received August 21, 2006; revision accepted for publication October 31,2006 .) 